\title{
Teaching Global Issues in an Undergraduate Program
}

\author{
Alina M. Zapalska*, Erik Wingrove-Haugland, Christopher LaMonica, Elizabeth Rivero \\ Department of Management, U.S. Coast Guard Academy, New London 06320, Connecticut, United States \\ *Corresponding Author: Alina.M.Zapalska@uscga.edu
}

Copyright (C) 2013 Horizon Research Publishing All rights reserved.

\begin{abstract}
In preparing cadets to be officers, the U.S. Coast Guard Academy (CGA) is committed to developing "the whole person." CGA has increasingly developed program-specific ways to achieve educational goals and learning outcomes. While character development and ethical education have long been important learning outcomes, today's CGA curriculum has incorporated multicultural concepts and inter-cultural perspectives to encompass learning about problems and issues that cut across national boundaries. This paper discusses how student learning, growth, and development can be achieved in an undergraduate program to ensure that graduates are prepared to meet the many challenges they will face throughout their professional careers and lives in an increasingly global environment.
\end{abstract}

Keywords International undergraduate education, multicultural concepts, inter-cultural perspectives

\section{Introduction}

Since September 11 2001, academic awareness of the importance and complexity of global issues and problems has increased significantly. Colleges and universities have long sought to prepare their graduates to become responsible and informed citizens; this increased awareness of the importance of global issues means that a college education is now expected to help develop an understanding of the interacting factors that cause poverty, social, economic and political injustice, inhumanity, conflict, discrimination, and environmental abuse. There is now a consensus regarding the importance of teaching international and global issues in an undergraduate education, but there is no clear and concise understanding of what "international undergraduate education" should be. This paper presents some examples of the efforts to teach global issues at CGA.

Every institution of higher education is unique, and must develop its own approach to teaching global issues. CGA is unique in that $100 \%$ of our graduates become Coast Guard Officers; as the first part of this paper notes, this has led to an emphasis on "the whole person" and on honor and character. While this emphasis informs the academic curriculum, it also includes many non-academic activities, including the cadet honor system and diversity programs. The American Service Academies Program (ASAP) is another example of a non-academic program which focuses on universal human values and how they apply to current global issues, conflicts, and problems.

The paper then presents some examples of academic courses and activities that provide students with knowledge of the world beyond their country's borders and help them understand how their actions can affect this world positively or negatively, and to develop an appreciation of cultural differences and similarities crucial to their ability to function in an interdependent world. These examples show how curriculum design and class activities can help students to appreciate the diversities and commonalties of human values and interests, and to see the world through the eyes of others. The last section provides conclusions on international undergraduate education, arguing that it must be proactive and must include learning experiences that advocate the understanding of both universal human values and the diversity of human cultures.

\section{Literature Review}

Globalization has exposed us all to the traits and practices of other cultures and has transformed the way businesses and governments conduct business. The problems and challenges that we face today: global warming, the decline of citizen interest and engagement in the political process, terrorist attacks, religious and ethnic conflicts, financial and economic crises, and the shift from a national to a global economy all call for adaptive, creative solutions that require a new direction in college education [1]. In response to these new global challenges, most academic programs now include global education as an important feature of their official curriculum; moreover, numerous research studies, policy reforms, and curriculum initiatives have been undertaken by teachers, policy makers and researchers in an attempt to understand and identify the best methods for having students learn about global issues and problems, and where and how citizenship education should be located and represented in college curricula [2-3]. While it is clear that global education is now recognized as a core educational goal in the 21 st century, it is less clear what exactly global competence or education is. According to the literature, a wide range of perspectives and practices has emerged, reflecting a considerable growth of interest in global 
education [4-5].

Across the educational literature, the conceptualization of global education has not been universal but in general it includes any effort to introduce global issues in the classroom [6]. Some have tried to give global education a much more precise definition that specifies a certain set of topics, issues, attitudes and pedagogical practices [7]. Hicks [8] defines global education as an approach to teaching that attempts to empower students with the knowledge, skills, and commitment required by world citizens to solve global problems. Pike [9] argues that global education entails the study of human conflict and cooperation, the independence of human systems, and the fostering of cross-cultural understandings, such as the development of empathy and perspective taking. Global education also aims to instill in students a global perspective and to develop the essential knowledge, skills, and dispositions necessary to live successfully in a world characterized by cultural and ethnic pluralism, increasing interdependence and limited natural resources [9-10].

Hicks adds that global education promotes the knowledge, attitudes and skills relevant to living responsibly in a multicultural, interdependent world [8]. Reimers [11] promotes the notion of global competency which he defines as the knowledge and skills people need to understand today's world and to integrate across disciplines so that they can comprehend global events and create possibilities to address them. Reimers also argues that global education should help to develop an appreciation for a world that is increasingly interconnected. According to this view, students require global skills, including knowledge of world geography and complex cultural literacy and world language skills to understand these interdependencies. Global competencies are also the attitudinal and ethical dispositions that make it possible to interact peacefully, respectfully, and productively with fellow human beings from diverse geographies [12]. Similarly, Merryfield et al. [13] argue that students need to develop an acceptance of different cultures, a concern with the world, an understanding of interconnectedness, and the value of world citizenship [13].

In light of the aforementioned, Suarez-Orozco and Sattin [14] highlight an alarming fact: at a time when youth around the world are in need of a solid cultural grounding and effective communication, collaboration and critical thinking skills, as well as the ability to become life-long learners, many schools do not meet the challenges posed by today's globalized world. Mansilla and Gardner [15] propose that, in order to succeed in this environment, beyond learning about world history and cultures, students must develop a "global consciousness". They define the acquisition of a global consciousness as the capacity to place ourselves and our circumstances within the broader frame of our contemporary world. Furthermore, they explain that three cognitive-affective capacities are at the basis of global consciousness as they understand it: global sensitivity (the awareness that local experiences are part of a larger matrix in the world), global understanding (the ability to reflect on worldwide developments in an informed way), and global self (the capacity to perceive oneself as a member of world society, thus promoting civic engagement and participation) [15]. Süssmuth [16] also recognizes the great responsibilities placed by globalization on educational systems. According to Süssmuth, academic institutions should include in their curricula the teaching of cognitive, emotional, social, and digital intercultural skills [16]. In her view, these skills are essential for students to be able to think outside their own familiar context, to diminish their fear of diversity and foster the understanding of the global context in which they live, and to have the capacity to communicate and gather information beyond their immediate milieu, thus integrating into globalizing societies [16].

Based on the above, this paper has been written to argue that global education is imperative to development of the skills, knowledge, and attitudes that are necessary for responsible participation in a democratic society and in a global community in the twenty-first century. In this paper, the authors argue that in order to effectively face the complexities of the today's global challenges, college students should develop both a global perspective and a global consciousness. Attaining global competency may require the use of several approaches that include the study of cultures, geography, languages, international issues, responsible citizenship in an interdependent world, and an exploration of global connections within local communities. The Coast Guard Academy (CGA) has long had a commitment to the enhancement of global dimensions of academic programs across all majors.

This paper contributes to the existing literature by arguing that global education is essential to students' development of knowledge, skills, and attitudes necessary for future employment and for building successful relationships in an increasingly interconnected and pluralistic society. Global education should focus on the interrelated nature of conditions, issues, trends, processes, and events, as well as emphasize specific world regions, problems, and cultures. CGA global education encompasses studies of specific areas or regions of the world as well as the in-depth examination of cultures or some aspect of a specific culture, such as its history, language, literature, religion, political organization, economic system, or current issues. This paper concurs with the work of Mansilla and Jackson [6] in that all programs and courses at the CGA have been developed so that the CGA students, upon their graduation, should be able to: (1) investigate the world beyond their immediate environment, framing significant problems and conducting well-crafted and age-appropriate research; (2) recognize perspectives, others' and their own, articulating and explaining such perspectives thoughtfully and respectfully; (3) communicate ideas effectively with diverse audiences, bridging geographic, linguistic, ideological, and cultural barriers; and (4) take action to improve conditions, viewing themselves as players in the world and participating reflectively. In sum, the CGA academic and nonacademic programs help to promote students' global sensitivity, global understanding, 
as well as a sense of global-self, through a range of dynamic, interactive, and diverse teaching methods and curricula.

\section{The U.S. Coast Guard Academy: Developing "The Whole Person"}

The U.S. Coast Guard Academy (CGA) is one of the five U.S. federal service academies. CGA's primary mission is to educate future officers of a multi-mission, maritime military force that is responsible for saving lives, protecting natural resources, enforcing maritime laws, and defending the nation. Cadets at CGA must demonstrate uncompromising ethical conduct in all personal and professional actions; they are expected to be loyal and accountable to the public trust while and to treat others with respect, fairness, and compassion. As military professionals, they are expected not only to be responsible for their own behavior, but to hold others accountable and to display devotion to the mission of the Coast Guard and the Department of Homeland Security.

CGA's holistic education includes academics, physical fitness, character and leadership development, as well as traditional academic courses. Its education and training programs seek to develop "the whole person" both inside and outside the classroom. Cadets are expected to develop intellectually, personally, ethically, socially, emotionally, physically, and spiritually within the four year undergraduate program. CGA's academic curriculum has included ethical education since 1876; CGA has had a required Moral and Ethical Philosophy course since 1989. While these academic efforts are important in developing cadets into leaders of character, non-academic efforts such as the Cadet Honor Concept and diversity programs also play an important role.

Since 1962, CGA has used a cadet-run Honor Concept to help create an Academy-wide culture of honor and respect. This culture is required to facilitate learning in all academic disciplines, and significantly enhances the climate in which cadets develop cognitive and leadership skills, as well as their ethical development. By living under the Cadet Honor Concept, cadets come to see honor as a moral imperative. Importantly, cadets enforce the Cadet Honor Concept, and hold other cadets accountable for violating it. The Honor system is thus a critical aspect of honor and respect education, not only because it leads cadets to behave honorably themselves, but also because it helps them develop the ability to demand honorable behavior from others, and to hold others accountable for dishonorable behavior.

The Cadet Honor Concept is reinforced by an Honor training program which begins the day after cadets arrive at CGA and continues until the day they depart. After taking the cadet oath, incoming cadets participate in a training session featuring small-group discussions led by faculty and staff facilitators, which focuses on the universal values behind the Constitution they have just sworn to support and defend. These training sessions continue throughout the summer and the academic year, along with discussions on gender relations and tolerance for diversity; they not only help to instill the core values of Honor and Respect into cadets, but also to create an Academy-wide climate of mutual trust and respect. Guest speakers contribute to this dialogue on honorable living by making cadets aware of the challenges they will face and inspiring them to hold steadfast to their honor when facing those challenges. The Cadet Honor Concept is an effective tool in developing ethical behavior in cadets and in helping them demand ethical behavior from each other.

In teaching global issues, one of the greatest assets of any educational institution is the diversity of its student body. In a diverse student body, many students will already have an understanding of global issues which other students lack. Since college-age students learn more readily from their peers than they do from instructors, focused diversity programs can provide an excellent venue for students to learn about global issues from each other. CGA has increasingly used diversity programs to allow cadets with various abilities, interests, and racial, socioeconomic, and ethnic backgrounds to create a community of learners regarding global issue.

While CGA has long used a Peer Educator System, the recent creation of a diversity peer-education system aligned with the higher education Multicultural Affairs model has created a system that promotes the larger diversity strategies of the Academy. Restructuring cadet cultural and diversity clubs under Diversity Councils and the Diversity and Inclusion Office has allowed the institution to meet the greater needs of the Academy while maintaining the integrity of affinity group organizations. For example, the CGA International Council, one of three councils of Diversity Council, supports, promotes, and strengthens the international dimension of CGA through various programs and activities. It provides cadets with learning experiences on unique cultural and social issues and promotes understanding of different cultures, religions, and traditions. It also exposes cadets to different cultures and provides them with positive experiences that will better prepare them for their future as Coast Guard officers in charge of a diverse workforce and interacting with foreign nationals in an increasingly global community.

The next sections of the paper illustrate some of the approaches CGA has used to develop responsible decision making about global issues. The examples illustrate that both academic and non-academic programs must involve all students in learning activities that provide awareness about the global issues in order to face the challenges of our globally integrated world.

\section{Universal Human Values and the American Service Academies Program}

It is tempting to think that only the leaders of nations need to understand global issues, and that the people of each nation simply need to support their leaders and their views of 
global issues. This view is understandable; since the people of a nation are less educated than their leaders, and have fewer resources to gain knowledge of global issues, it is tempting to conclude that only national leaders have the knowledge required to make good decisions regarding global issues. It is particularly tempting for members of the military to believe that they do not have to understand global or ethical issues, and can merely follow the orders of their superiors. History has shown, however, that leaving global issues up to leaders is inadequate and dangerous; the absence of an informed and active citizenry has led to many atrocities due to the greed and ambitions of the ruler.

Adolf Hitler is the classic example of absolute dictatorship leading to the commission of atrocities. His subordinates never questioned his orders or formed their own opinions about the morality of their actions; they merely synchronized their morals to their leader's ideals and blindly supported his every command. The result was a Holocaust in which millions of deaths were seen a justified by dubious goals such as the creation of a pure Aryan race. The Holocaust is a perfect example of immoral behavior masquerading as moral behavior sanctioned by law; it is clear evidence that citizens and members of the military must question whether it is always morally wrong to break the law or to disobey established authorities.

Examples like the Holocaust show that true leadership is not about absolute conformity, but rather developing effective followers who are committed to the organization and share common goals. Good leaders are those who promote open and upward communication and accept constructive feedback on strengths and weaknesses. Checks and balances and transparency are necessary to ensure that actions and decisions reflect the shared goals of the people, not merely the personal agenda of the leader.

Because it is also the embodiment of terrorism, studying the Holocaust is particularly important for future offices in the Department of Homeland Security, who are tasked with the duty of defending citizens from acts of terror, which are arguably the largest threat to U.S. national security today. The tactics that the Nazis used, like killing Polish citizens who spoke out against their politics, were the essence of terrorism. The world turned a blind eye to the atrocities committed during the Holocaust, and students must learn from this historical mistake in order to avoid repeating it.

The CGA American Service Academies Program (ASAP) provides educational activities that focus on the Holocaust and related contemporary moral dilemmas. The ASAP not only educates students about the past but also stimulates dialogue about the present and the future. Throughout the program, cadets work to gain a better understanding of pre-war Jewish life, its subsequent devastation, and the moral issues involved. The program begins in the U.S., at the United States Holocaust Memorial Museum in Washington, D.C. and the Museum of Jewish Heritage, where cadets and midshipmen learn about Jewish life, the Holocaust, and modern genocide from scholars, survivors, and exhibitions.
It culminates with a trip to actual concentration camp sites in Europe, where cadets learn from Holocaust survivors, Polish officials, and the historical sites themselves.

The ASAP provides many important lessons related to leadership, morality, and global issues. By learning from the erroneous decisions made by German leaders, future CG leaders will be able to appreciate the importance of internalizing the core values rather than allowing the leaders' morals guide their actions. Cadets attend many leadership courses at CGA, but the ASAP emphasizes the essential points of good leadership, which cannot be learned solely from textbooks. The ASAP provides a unique opportunity to learn from negative examples of bad leadership, and to develop positive approaches to leadership.

Today, when the U.S. and the Coast Guard are searching for ways to promote diversity and eliminate racism, the ASAP program is particularly relevant. The leading causes of the Holocaust occurred were racism, ignorance, and fear of diversity. Once all the Holocaust survivors have passed away, it will be the ASAP participants' responsibility to keep these memories and stories alive, and to ensure that atrocities like the Holocaust never happen again. It is an excellent example of how to use a non-academic program to teach global issues and the skills required to rise up to them.

\section{Business Undergraduate Education and International Issues}

While any academic course in economics will help improve students understanding of global issues, international competencies demand a different implementation of international business and economics training at the undergraduate level. International business and economics education should offer pedagogical techniques that allow students to function within foreign cultures and to respond critically to the idea of doing business with other countries. An understanding of the other countries and their different economic systems, different value systems are important. Understanding the status of the family, the role of women and minorities in professional activities, and the importance of culture, religion, and education, the value of tradition and culture, and the religion and its influence on governing powers should be included in courses that taught issues on globalization.

The USCGA has adopted several goals for the international undergraduate education and they include: (1) identifying common human problems in different societies and historical settings; (2) identifying the ways in which community and state are involved in the transnational flow of goods, services, information, and people; (3) recognizing in other cultures the needs, behavior, life experiences, and existential concerns common to all people; (4) comprehending long-term global trends such as population growth, economic development, the patterns of resource use, the dispersion of nuclear weapons and the possible 
consequences of these trends; (5) identifying technologies, institutions, languages, and beliefs that link people in many regions of the world; (6). considering the current and possible consequences of terrorism, nuclear and biological war for self and others of different world views; (7) perceiving that different life styles and cultures have different impacts on our lives; and (8) identifying alternatives facing public policy-makers and lend support to policy alternatives that seem most appropriate.

International undergraduate education must provide students with opportunities to study economic, political, cultural, ecological and technical aspects of globalization so that students are able to see differences and similarity in characteristics among those systems. Such study should help students recognize the interdependence of the global economies and see how they are affected by the global systems and how they can develop strategies to live within them. Students need to engage in discussions and think about the causes, effects, and solutions to global issues and problems. An international undergraduate education program should also allow students to understand their roles in developing solutions to the issues and problems within the context of global economy. Students should be able to understand the difference between opinion and perspective on international issues.

International education involves learning about problems and issues that cut across national boundaries and about the interconnectedness of systems - ecological, cultural, economic, political, and technological. International education teaches a realization that while individuals and groups may have life experiences they also have common needs and wants. Students should be introduced to the strategies, skills, and dimensional issues that define global affairs. They should be offered materials that enable them to be well informed and promote decision-making for solutions and consequences to global problems involving global issues.

For example, in International Economics Course, Comparative Economic Systems issues are covered as international requirements, and are being offered to consolidate and extend the students' basic knowledge of economics. The course of International Economics at the Coast Guard Academy focuses on an economic system and its role in and impact on a global economy. International Economics course at the CGA is a foundation course for students studying international business and as such plays a critical role in developing student understanding of the global business environment. Since the students come from a range of cultural, academic, and social backgrounds, the course attempts to introduce them to critical elements in the global environment and to encourage them to identify the implications for firms involved in international business. The course introduces a range of economic principles and applies this knowledge to an understanding of the economic systems in the context of the global economy.

This is an introductory course that aims to build understanding and critical reflection rather than to develop strong research skills. The specific aims of the course are for students to develop an understanding of those factors that facilitate or restrict international business, to gain an understanding of relationships affecting international business, and to learn how management principles are influenced by different cultural contexts. The curse is geared to introduce students in a sensitive way to different cultural traditions, new ways of looking at the world, and foster intercultural insight, understanding and sensitivity. Students are expected to be able to examine their own perspectives, attitudes and cultural backgrounds, and even start changing certain patterns of behavior according to new insights and trends with respect to those of different backgrounds, culture, religion and color of skin. They have to learn how to judge the lifestyles, modes of behavior, values and world views of others who are very different than they are.

The course consists of an overview of the international business environment architecture, a historical overview of the development of international business in the twentieth century, an examination of the global marketplace, and an exploration of the factors that facilitate and limit international business including different legal systems. This includes factors like culture, technology, and national, regional, and supranational organizations and policy. The teaching approach is one that emphasizes student participation and interaction with each other and the lecturer. This is achieved through a number of in-class group exercises that culminate in the students presenting work to the class. These exercises are particularly useful when students are comparing alternative legal systems and cultural patterns and their implications for international business.

During the course there are three of specific topics that receive coverage. The first is a debate as to whether globalization is actually occurring. The standard view is contrasted with the idea that globalization is not in fact happening but that there is increased integration between the triad of the European Union, Japan, and North America. The students have to evaluate the two views and identify the implications of the outcome for international business strategy. The second topic is an analysis of how increased contact between countries is influencing the ways in which firms do business. Of particular relevance here is the effect of international contact on the management culture.

Students are expected to conduct research and prepare a term paper. The purpose of the term paper is to examine the relationship between economic theory and practice; and was designed to provide an opportunity to learn about a selected country's culture and political and economic systems and measure their impact on international business. Students are expected to: (1) analyze and describe the impact of different cultures, economic systems, economic outcomes, and government policies on global economy; (2) evaluate the lack or presence of economic efficiency and its effect on global economy; (3) identify the role of growth and development of the private sector on economic efficiency of global economy; and (4) reflect on the relationship between the political, social, and cultural influences present in the 
country and their effects on peace and safety.

The term paper is evaluated on several levels that included aspects of value, balance, clarity and relevance to the subject of an economic system. Students are directed to issues that dealt with assessment, including the unacceptability of plagiarism or cheating. On completion of this course, successful students are able to demonstrate an understanding of economic principles within a context of an international economy, evaluate economic efficiency, and apply their knowledge to current problems of an international economy within various economic and political system and cultural settings.

This course is an excellent vehicle for exposing students to the elements of the international environment and the interaction between those and the operation of international business. As a result of completing this course it is expected that students not only will have a better understanding of international business but that they also will have a greater appreciation of the diversity of characteristics that exist throughout the world. The course provides: an awareness and appreciation of other cultures of the world and in-depth understanding of global issues and events as well as cross-cultural awareness and a general understanding of the defining characteristics of world cultures, with the emphasis on understanding similarities and differences.

\section{Teaching Global Issues through Moral Philosophy}

While International Economics focuses on global issues, Moral and Ethical Philosophy provides an example of how a course that is not specifically focused on international education can still help promote understanding of global issues among undergraduates. This required core course covers the history of Western moral philosophy (Plato, Aristotle, Epictetus, Hobbes, Locke, Hume, Kant, Mill, Rawls, etc.) as well as contemporary moral issues. Although global issues are addressed specifically to some extent, especially issues pertaining to Just War Theory and famine relief, the focus of the course is on moral philosophy and applied ethics. This is a very discussion-focused course, in which students are encouraged to examine their own moral views by engaging in dialogue with the great thinkers of Western ethics and to develop the ability to analyze and evaluate moral issues by examining arguments on both sides. The course culminates in a research paper which applies several moral philosophies to a contemporary moral issue; while some students choose to address international issues in this paper; many others choose issues that are not specifically international.

While the Moral and Ethical Philosophy course does not focus on global issues, it nevertheless helps promote global awareness and understanding in many ways. For example, very early in the course we address the issue of cultural relativism, reading Michael Brannigan's "Cultural Relativism and Cultural Diversity" and Louis Pojman's "Ethical Relativism." Students are led to see that rejecting the ethnocentric view that their own culture's values are superior to those of all others need not lead to embracing the relativist conclusion that it is impossible for any culture's values and practices to be better or worse than any other culture's values and practices. While cultural relativism claims to promote toleration of other cultures, this claim is problematic, since if a culture's values include intolerance of other cultures, cultural relativism implies that that we cannot criticize other cultures for being intolerant. By avoiding any evaluation of the values of other cultures, cultural relativism actually discourages learning from other cultures, since it asserts that it is impossible for the values or practices of other cultures to be better than our own.

During class discussion, we use the example of sati (or suttee), in which a widow joins her dead husband on his funeral pyre and is burned alive, to show that we must set aside our own culture's preconceived notions to understand the practices of other cultures, whether or not that leads us to tolerate them. After initially trying to tolerate and regulate sati, the British banned it; it continued to be practiced, however, because widows seemed to engage in it voluntarily. Efforts to eliminate sati did not become effective until the British realized that the practice was not based on religion, but on economics; there was no mechanism for widows to support themselves. As soon as programs providing economic support for widows were instituted, the practice of sati rapidly declined.

The point of this case study is to show that we must see a value or practice from the perspective of those engaged in it in order to understand it, and that understanding the practices of other cultures is a necessary precondition for making an informed decision to tolerate them or try to eliminate them. Cultural relativism is correct in asserting that we should approach the practices of other cultures with an open mind; trying to see the practice from the perspective of those engaged in it is essential to understanding the practice. Assuming that a practice is irrational is almost always incorrect; members of other cultures have reasons for doing what they do. Contrary to cultural relativism, however, understanding the values and practices of other cultures may not always result in tolerating them; a careful understanding of a practice may support the conclusion that it ought to be changed or abolished. Even in this case, however, it is essential to see the practice not only from multiple cultural perspectives, but also from multiple disciplinary perspectives. Only by understanding the reasons for a cultural practice can our students make responsible decisions which reflect both the legitimate diversity of cultural practices and the universality of human rights.

\section{Teaching beyond the Traditional Canon of International Relations}

In academic courses that focus on international issues, whose work is taught and how it is taught is at least as important as what is taught. These concerns are especially relevant within the political science subfield of International 
Relations (IR) as, over the past few decades, IR has become one of the most popular areas of academic study. Given all that has been said above, one would expect IR study to be increasingly relevant to a wide range of future careers. Its very title appeals to those who aim to have broader, more global, approaches not only to political science and the social sciences but to virtually every other area of academic inquiry. On the surface, IR seems to offer an avenue for investigating areas of common human concern, or for contemplating 'global' interests, or even for identifying parallels of political thought and practice. However, as is the case in many other academic disciplines, the intellectual framework for IR study remains stubbornly parochial in orientation. That is, the classic contributions to the field remain steadfastly tied to the Western canon of political theory and historical examples used to support one or another theory also tend to come from within the West. Moreover, contributors to the field are almost all from Western universities. At first blush then, the subject of IR might appear to be a great venue for contemplating the 'global'; however, it requires teachers of IR to stretch the discipline beyond its traditional intellectual framework.

Examples of parochially Western biases in political science texts abound but two will suffice here. First, the popular Baylis \& Smith [17] text, entitled The Globalization of World Politics: An Introduction to International Relations, contains contributions from twenty-seven of the leading scholars on the subject of IR; of those, all twenty-seven are from Western universities. That is, while the title refers to the "globalization" of the subject, authorities within the field do not appear ready to accept perspectives from outside of the West; at best, if there are any non-Western perspectives to be considered, they are described and explained by a Western contributor, as if they were the only proper authorities available. As we enter the $21^{\text {st }}$-century, leading texts on IR still seem to demonstrate that to be considered an "authority" on IR, the scholar is greatly aided by having a formal affiliation with a Western academic institution. Just as the Italian saints have historically had a home court advantage due to their proximity to Rome, the traditional Western scholar still seems to enjoy a seemingly unfair advantage in the social sciences. In the literature [18], this has been described as a kind of Foucauldian problem, whereby the source of IR knowledge remains closely aligned with traditional Western powers.

A second example has to do with content and, again, this is far from being an isolated case. The popular university text on Comparative Politics text by Thomas Magstadt [19], entitled by Nations and Governments: Comparative Politics in Regional Perspective, offers students a broad survey of regional cultures and histories that, it is argued, ultimately led to the formation of different governing institutions. It is a wonderful book, but there are glaring problems that point to a Western bias that skirts important historical events, elsewhere in the world, and entire geographical regions. For example, in the section on Asia, there is no mention of the Khmer Rouge/Pol Pot regime in Cambodia (during which perhaps as many as one million people were killed); and, more broadly, there is a glaring neglect of politics in the Pacific region of the world, with virtually nothing said about Australia and New Zealand. Throughout, there is a lack of inclusion of non-Western perspectives as if to say that the voices of the less powerful matter less to the power-oriented subject of political science. And this is far from unique to Magstadt's text; it is a pattern found throughout the field.

Many continue to deem these Western-centric arrangements within "authoritative texts" appropriate; after all, a great many Western ideas are certainly meritorious and worthy of careful consideration in the classroom, for citizens of both free democratic societies and also where illiberal and undemocratic forms of governance prevail. But the supporters of this institutional bias, that lead to the currently dominant structure of political science "knowledge," miss two crucial points: (1) Inclusion of historical experiences and thoughts from other parts of the world can emphasize important parallels of experience and thought (that have thus far been marginalized); and (2) The ongoing marginalization of the non-Western reader often leads to conspiratorial thoughts and lesson plans that are targeted at these very Western sources of "authority." The latter is particularly troubling as, upon reflection, many of these anti-Western discussions in the classroom ultimately lead to anti-Western policy stances among, not only "radical" rabble-rousers of all kinds, but government leaders.

On the whole, progress at becoming more geographically, culturally, and linguistically inclusive has been painfully slow. Within IR, even the most basic task of identifying political realists, liberals and idealists in non-Western contexts remains elusive to the majority, as if everything from political astuteness to political innovation and ideas on freedom occur only in occidental contexts; for obvious reasons, nothing could be further from the truth. Yet, for a variety of professional, practical, logistical and other reasons, the majority of the world's scholars and students has not yet dared to question the dominance of Western "classics" of political science inquiry as they are generally taught in academic institutions. Within IR, a certain amount of lip-service has been paid to this issue but the traditional intellectual framework remains firmly based on the classics of Western political science - the "right" answers remain parochially Western.

In an effort to help correct these biases, the teacher of IR needs to reach beyond the traditional canon, as it is found in traditional IR textbooks, and contemplate the thoughts and deeds of non-Western political theorists and practitioners. This effort is still required, even as the world rapidly becomes a smaller place, even as contemplation of the 'global' becomes more pressing each day. The discipline of IR has the pretense of being global but, as discussed here, even a cursory look at the source and content of IR scholarship demonstrates that the task of globalizing the subject of international relations remains.

One could sum the problem up in Rudyard Kipling's oft-quoted phrase: "What do they know of England who only 
England know?" For it is only by moving our perspectives beyond the parochial that we can begin to understand that they are so often, so narrowly focused; the hope is that by placing our perspectives within a broader context, we might be better able to understand and, perhaps, appreciate those perspectives. Even better, let us educate our students of the oft-quoted phrases, as above, yet also remind them that these very same philosophical questions, which are at the root of all social science inquiry, are to be found throughout the world. As an example, Indian students are usually aware of Swami Vivekandanda's provocative question: "How do we know?" In the classroom, teachers should emphasize that there are parallels of political thought and behavior found throughout the world - they are to be found in the classics of the ancient world, from Egypt to Mesopotamia to China, and in our modern world, if one bothers to seek them out and to listen for them. In the classroom, it is our responsibility to remind them of this simple, if not immediately obvious, fact.

\section{Global Issues in the Spanish Foreign Language Classroom}

We live in a postmodern world in which borders, due in large part to the development of technology, are no longer an impediment to the immediate dissemination of information and the transit of ideas, currency, merchandise and individuals, consequently interconnecting vast and heterogeneous areas of the globe. Furthermore, and on a sadder note, the growing inequality of opportunities world-wide accounts for the transnational mobility of migrants in search of better personal and professional prospects. This new configuration of the international scenario calls for a new kind of citizen capable of acknowledging and appreciating cultural differences as well as seeing the world through the eyes of others of different nationality, ethnicity, religious affiliation and socio-economic background. Now more than ever before developing language and cultural competencies that facilitate communication, understanding and tolerance is an overarching need. Therefore, teaching foreign languages in the undergraduate classroom is vital because of the above-mentioned new possibilities that do, however, present new challenges.

Learning a foreign language enriches students' lives by opening up a different perspective on other cultures and their perceptions and idiosyncrasies. One of our basic goals here at the Coast Guard Academy (CGA) in the Spanish classes we offer (Elementary Spanish I, II and I-II; Intermediate Spanish I and II; Advanced Spanish, Conversational Spanish and Coast Guard Spanish) is for students to realize that a language's grammar and vocabulary is so much more than rules and a word bank, but are instead dynamic expressions of a particular way of understanding the world. By creating an environment of immersion in which all communication is carried out in Spanish, students are expected and encouraged to leave their comfort zone, to "live" inside the culture, and see and interpret reality through a new set of cultural lenses.

Another significant aspect of our Spanish language program is that the teaching of the language is never detached from the study of the source culture. Language and culture, subsequently, form an intertwined duality that expresses the multifaceted angles of the diverse Hispanic world. Even in the basic levels of our Spanish program we resort to authentic cultural materials to complement the study of the language. These authentic cultural materials include, but are not limited to, short stories, poems, music, artwork and films. In a digital world such as contemporary society is, and one in which images and technology play a predominant role in our students' lives, the recourse to internet applications to enhance students' cultural awareness like, for example, YouTube and Raphsody, just to mention a couple of electronic sites, has proved very successful in the language classroom and has fostered the creation of a relaxed and engaging atmosphere that helps students embrace a foreign culture.

When exploring Hispanic culture we have numerous objectives in mind: a) dispelling the myth of its homogeneity b) presenting the different historical frameworks that have shaped the diverse Hispanic societies c) acquainting students with its most relevant artistic manifestations and its key cultural figures in a broad context that encompasses artists of different geographical areas, ethnicity, sex, age, etcetera, d) studying the Hispanic presence in the United States, its influence and contributions, and, most importantly e) creating open-minded, well-rounded, caring individuals capable of surpassing language and cultural barriers, appreciating differences and commonalities in terms of values, traditions, lifestyles, backgrounds, as well as actively promoting international understanding and cooperation.

A careful selection of textbooks and class materials plays a significant role in meeting these goals. When teaching Advanced Spanish, the highest level language and culture course we offer at CGA which is taught every year in the fall semester, the CGA Spanish instructors alternatively use the following textbooks: El cuento hispánico. A Graded Literary Anthology (McGraw Hill), Voces de Hispanoamérica. Antología Literaria (Thomas \& Heinle), and Aproximaciones al estudio de la literatura hispánica (McGraw Hill). These textbooks offer an ample variety of literary works that represent the vast regions comprising the Hispanic world. By analyzing texts from Spain, Mexico, the Caribbean, the Andean region and the Southern Cone, just to mention a few differing cultural geographies, students not only learn about the different accents and regional dialects, but they also understand the complexity and variety of Hispanic culture, and the fact that the Hispanic world is not a uniform monolithic unity but a rich and dynamic composite of different traditions, experiences, perspectives and cultural and ethnic legacies. Students can easily apply this insight to other cultures as well and thereby enhance their understanding of the fluid nature of cultures, and consequently liberate themselves from fixed, pre-conceived notions of cultural identity. 
In order to appreciate the variety of Hispanic cultures in existence, a basic knowledge of the most significant historical events that have helped shape it is required of students. Therefore, when selecting the reading assignments for the course, the instructors always include some literary texts that familiarize students with relevant historical episodes across the Spanish-speaking world. For example, the short story "Nos han dado la tierra" by Mexican writer Juan Rulfo is a reflection on the Mexican Revolution, while Argentinean writer Luisa Valenzuela's short stories "Los censores" and "Los mejor calzados" deal with censorship and repression, respectively, during the dictatorship in Argentina. Films are also a powerful tool to introduce historical aspects in the language classroom. For example, the CGA Spanish instructors refer to Spanish films such as La lengua de las mariposas (Butterfly) and El laberinto del fauno (Pan's Labyrinth) to discuss Francisco Franco's coup d'eta and the Spanish Civil War. My emphasis on providing students with a historical background is based on the belief that understanding a culture's history enables us to better understand its values, norms and viewpoints.

Finally, the twenty-first century has brought about a vibrant interconnected world. This changed reality demands a new kind of citizen, one possessed with the skills and competencies to overcome language and cultural rifts, and the necessary amplitude of mind to respectfully acknowledge differences and similarities in an effort to build a more just, equal and safe global community. The undergraduate foreign language classroom is an ideal setting to develop students' critical, communicative and cultural skills and help them meet the challenges posed by our interdependent world.

\section{Conclusions}

The U.S. Coast Guard Academy has created an environment with institutional goals for student learning, growth, and development both inside and outside the classroom to ensure that the CGA graduates will be prepared to meet many challenges they will face throughout their professional careers and lives. The CGA mission statement and strategic plan identify goals and designate the Academy's faculty, officers and administrative staff who are responsible for creating, developing, and maintaining successful programs where cadets apply knowledge and skills that they acquired in the classroom to global issues they will continue to grapple with after their graduation.

In our globally integrated world, undergraduate education has promoted the development of curriculum that supports understanding global issues and the interdependence of nations today. CGA cadets are being educated so that when they enter their professional career they are motivated to take steps for justice and peace, against inequality, discrimination and oppression as well as act against terrorism, and misuse and devastation of natural resources.

Based on examples provided in this paper, the authors argue that today's college education should focus on the interrelations of cultural, economic, and political systems. Academic programs need to provide appropriate learning opportunities so that students develop an understanding of context and complexity, tolerance of ambiguity and uncertainty, and sensitivity of oversimplification of local, regional and global conflicts and issues. CGA graduates are expected to become aware that all global activities depend directly or indirectly upon and influence the global cultural, political and economic environment. Through linking the present with the past and future, students can gain a new and innovative vantage point for questioning proposed solutions, or exploring and in search of more effective alternatives.

The purpose of this paper is to encourage other academic institutions to evaluate their curricula in the context of issues of diversity in internationalization and globalization. Based on the success of the courses and programs presented, the suggestions proposed can serve as an outline for other institutions considering similar educational programs. International undergraduate coursework that provides intercultural competence and knowledge, promotes continued learning through both informal and formal means, and provides contested knowledge about global issues will enhance students' ability to be both productive and responsible citizens of their nation and of the world.

\section{REFERENCES}

[1] Ch.Olsen, An Integrated Approach For Advancing Campus Internationalization. Presentation to GATE Fellows, University of Maryland College of Education. College Park, MD, 2008 .

[2] M. Merryfield, The challenge of Globalization: Preparing Teachers for a Global Age. Teacher Education \& Practice: The Journal of the Texas Association of Colleges for Teacher Education, 24(4), 435-437, 2008.

[3] P. Stearns, Educating Global Citizens in Colleges and Universities: Challenges and Opportunities. New York, NY: Routledge, 2008.

[4] M. Green, M. C. Olson, Internationalizing the Campus: a User's Guide. Washington, DC: American Council on Education, 2008.

[5] J. Johnson, J. Spalding, Internationalizing the Curriculum. In J. Gaff \& J. Ratcliff (Eds.), Handbook of the Undergraduate Curriculum (pp. 416-435). San Francisco, CA: Jossey-Bass, 1997.

[6] V. Mansilla, A. Jackson, Education for Global Competence: Preparing Our Youth to Engage the World. New York: Asia Society. Running Head: Internationalizing Teacher Education 17, 2011.

[7] C.L. Olsen, M.F. Green, B.A. Hill, Building a Strategic Framework for Comprehensive Internationalization. Washington, DC: American Council on Education, 2005.

[8] Hicks, D. (2007). Responding to the world. In D. Hicks \& C. Holden (Eds.) Teaching Global Dimension: Key Principles 
and Effective Practice (pp. 3-13). New York, NY: Routledge.

[9] G. Pike, Global Education as National Identity: In Pursuit of Meaning. Theory into Practice, 39, 64-73, 2000.

[10] M.E. Gillion, Global Education and the Social studies. Theory into Practice, 20, 169-173, 1981.

[11] F.M. Reimers, Educating for Global Competency. In J.E. Cohen and M.B. Malin (Eds.), International Perspectives on the Goals of Universal Basic and Secondary Education, 183-202). New York: Routledge, 2009.

[12] F.M. Reimers, Leading for Global Competency, Teaching for the 21 st Century, 67(1), 2009.

[13] M. Merryfield, J. Lo, S. Po, M. Kasai, Worldmindedness: Taking off the Blinders. Journal of Curriculum and Instruction, 2(1), 6-16, 2008.

[14] M. M.Suarez-Orozco, C. Sattin, Introduction: Learning in the Global Era. In M.M. Suarez-Orozco (Ed.) Learning in the Global Era. International Perspectives on Globalization and Education (pp. 1-43). Berkeley \& Los Angeles: Univ. of California Press, 2007.
[15] V.B. Mansilla, H. Gardner, H. From Teaching Globalization to Nurturing Global Consciousness. In M.M. Suarez-Orozco (Ed.) Learning in the Global Era. International Perspectives on Globalization and Education (47-66). Berkeley \& Los Angeles: Univ. of California Press, 2007.

[16] R. Süssmuth, On the Need for Teaching Intercultural Skills: Challenges for Education in a Globalizing World. In M.M. Suarez-Orozco (Ed.) Learning in the Global Era. International Perspectives on Globalization and Education (195-212). Berkeley \& Los Angeles: Univ. of California Press, 2007.

[17] J. Baylis, S. Smith. The Globalization of World Politics: An Introduction to International Relations, 5th Edition, Oxford University Press, 2011.

[18] C. LaMonica. Working on non-Western perspectives in both theory and practice, in R. Shilliam, ed., International Relations and Non-Western Thought, Routledge, 227-238, 2011.

[19] T. Magstadt, Nations and Governments: Comparative Politics in Regional Perspective, Wadsworth Thomson, 2005. 